\title{
Synthesis of a New Potential Conjugated TAT-Peptide-Chitosan Nanoparticles Carrier via Disulphide Linkage
}

\author{
Haliza Katas, Nik Nur Shamiha Nik Dzulkefli, and Shariza Sahudin \\ Drug Delivery and Novel Targeting Research Group, Faculty of Pharmacy, Universiti Kebangsaan Malaysia, \\ Jalan Raja Muda Abdul Aziz, 50300 Kuala Lumpur, Malaysia \\ Correspondence should be addressed to Haliza Katas, haliz12@hotmail.com
}

Received 20 February 2012; Revised 23 April 2012; Accepted 23 April 2012

Academic Editor: Chunyi Zhi

Copyright ( $\odot 2012$ Haliza Katas et al. This is an open access article distributed under the Creative Commons Attribution License, which permits unrestricted use, distribution, and reproduction in any medium, provided the original work is properly cited.

\begin{abstract}
Chitosan and TAT peptide have been widely investigated as delivery systems for various biomolecules such as plasmid DNA, oligonucleotides, and siRNAs. Conjugation of chitosan with TAT-peptide was therefore expected to produce a carrier with enhanced ability to facilitate cellular uptake. In this study, chitosan nanoparticles (CNs) were prepared by ionic gelation method prior to conjugation with TAT-peptide via disulphide linkage (CN-TAT). The conjugation was performed at various TAT-peptideto-chitosan weight ratios ranging from $0.008: 1$ to $0.125: 1$. siRNA as a model biomolecule was loaded by adsorption onto the CN-TAT. Nanosize range particles were produced with a size range of less than $700 \mathrm{~nm}$ depending on TAT-peptide concentration used. HPLC and Raman spectrometry analysis revealed that TAT-peptide was successfully conjugated to the CN via disulphide linkage. siRNA loading efficiency for CN-TAT was $93 \% \pm 0.01$. In vitro cytotoxicity studies showed that CN-TAT has relatively low toxicity. In conclusion, TAT conjugated onto $\mathrm{CN}$ via disulphide linkage was successfully synthesized, and its low cytoxicity demonstrates a potential for its use as a vector for biomolecules.
\end{abstract}

\section{Introduction}

Various nonviral carrier systems have been developed to enhance delivery of various biomolecules into cells particularly nucleic acid-based molecules such as plasmid DNA, oligonucleotides, and small interfering RNA (siRNAs). There are, however, barriers to effective delivery of these molecules since most nucleic acids are rapidly degraded by nucleases and macrophages. Hence, a degree of protection is required to be incorporated into their delivery system. Liposomalbased formulations and cationic polymers have been extensively studied. Unfortunately, liposomal-based formulations generally experience cell toxicity [1], are rapidly cleared from the bloodstream [2], and are relatively large in size [3]. Positively charged cationic polymers can effectively bind to and protect nucleic acids such as DNA, oligonucleotides, and siRNAs. Cationic polymers frequently used as carriers include poly(l-lysine) (PLL), polyethylenimine (PEI) [4], and chitosan [5]. In contrast to PLL and PEI which are synthetic and nonbiodegradable, chitosan is a more ideal candidate as a gene carrier due to its excellent biodegradability and biocompatibility. In addition, the functional groups on its structure allow conjugation and coupling with targeting ligands.

The ability of chitosan to protect nucleic acids from nuclease degradation resulted in its low cellular uptake [6]. Thus, this had limited its use as a gene carrier. Conjugating TAT-peptide to chitosan nanoparticles is expected to enhance cellular uptake of these nanoparticles due to the reported ability of TAT-peptide to translocate across cell membranes [7] and, therefore, could enhance the delivery of bioactive molecules into a variety of cell types [8].

A study on conjugation of cargo with TAT-peptide has been reported [9], where TAT-peptide was conjugated with the chitosan derivative. O-carboxylmethylated chitosan (O$\mathrm{CMC}$ ) was coated around the magnetic nanoparticles and their drug delivery effectiveness was shown to be highly dependent on the modulation of magnetic field [10]. In this study, nanoparticles made from chitosan were conjugated directly with TAT-peptide via disulphide linkage as the linkage has been reported to result in high biological activities $[11,12]$. The attachment of TAT-peptide to its cargo, however, is also dependent on the size and chemical properties of a particular cargo. Attempts, therefore, have been made 


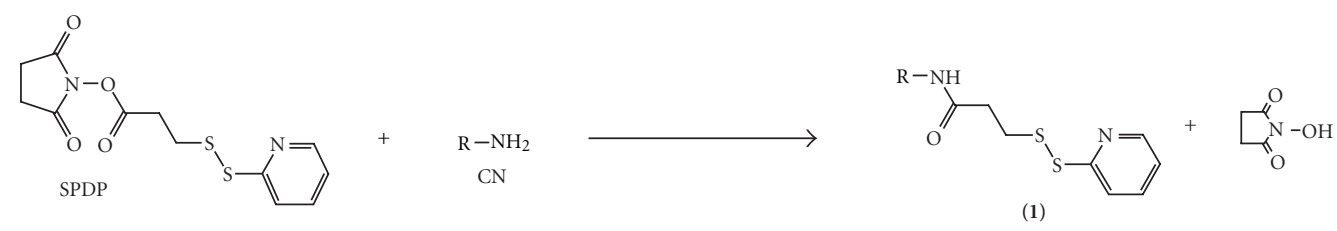

(a)

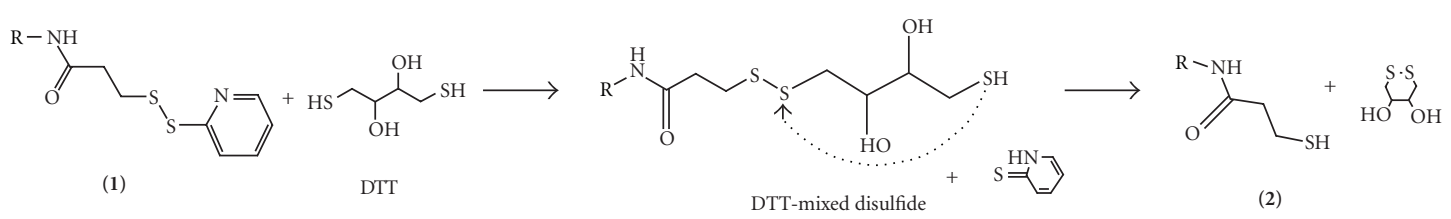

(b)
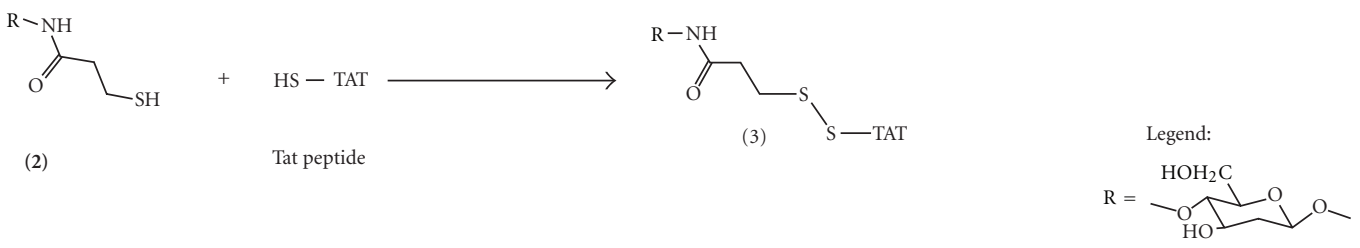

(c)

FIGURe 1: Proposed mechanism reaction of SPDP, CN, and DTT. (1) CN with 2-pyridyldithio end group, (2) CN with S-H end group (CN-S-H), and (3) CN-TAT.

to optimise the formulation and characterise the resultant conjugated products. As the nanoparticulate system was developed for delivery of therapeutic nucleic acids, siRNA was used as a drug model due to its proven specificity and being robust. In addition to the synthesis of these TAT-CN nanoparticles, the efficiency of siRNA loading and binding as well as their cytotoxicity effects was also studied.

\section{Experimental}

2.1. Materials. Chitosan (molecular weight of $190 \mathrm{kDa}$ ) with a $75-85 \%$ degree of deacetylation (DD) was obtained from Sigma-Aldrich, while pentasodium tripolyphosphate (TPP) was obtained from Merck, Germany. N-succinimidyl 3-(2pyridyldithio) propionate, dithiotreitol, and dimethyl sulfoxide (DMSO) were obtained from Sigma-Aldrich. siRNA targeting against pGL3 luciferase gene (sense sequence: $5^{\prime}$ GAUUAUGUCCGGUUAUGUAUU-3') and TAT-peptide, GRKKRRQRRRPPQC-NH $\mathrm{N}_{2}$, was purchased from Dharmacon (USA) and Innovagen (Sweden), respectively. V79 cell line (fibroblast cell derived from Chinese hamster lung) was purchased from ATCC, USA. Acetic acid (System), Acetonitrile (BDH Prolabo, UK), and trifluoroacetic acid (Fluka) were all of analytical standard.

\subsection{Method}

2.2.1. Preparation of Chitosan Nanoparticles. Chitosan nanoparticles (CNs) were prepared using ionic gelation method. A volume of $1.2 \mathrm{~mL}$ of TPP $(0.1 \% \mathrm{w} / \mathrm{v})$ was added dropwise to $3 \mathrm{~mL}$ of $0.2 \% \mathrm{w} / \mathrm{v}$ chitosan (chitosan to TPP weight ratio $6: 1, \mathrm{pH} 3.2$ ) under constant magnetic stirring at room temperature for $30 \mathrm{~min}$. CNs were then incubated for another $30 \mathrm{~min}$ before further use or analysis. CNs were harvested by ultracentrifugation (Beckman Coulter) at $48,583 \times \mathrm{g}$ for $30 \mathrm{~min}$. The supernatants were discarded and $\mathrm{CNs}$ were resuspended in filtered (Millex GP Filter Unit, Millipore, $0.20 \mu \mathrm{m})$ distilled water.

2.2.2. Conjugation of Chitosan Nanoparticles with TATPeptide. CNs were conjugated with TAT-peptide (CN-TAT) through disulphide linkage using a method reported by Zhao et al. [9] with some modification.

(a) Activation of CN Surfaces. CN surfaces were activated by yielding 2-pyridyldithio-end group on its surface by the following steps. A volume of $2 \mathrm{~mL} \mathrm{CN}$ suspension $(20 \mathrm{mg} / \mathrm{mL})$ was mixed with $2.5 \mathrm{~mL} \mathrm{~N}$-succinimidyl 3-(2pyridyldithio) propionate (SPDP, $20 \mathrm{mM}$ ) in DMSO. After $60 \mathrm{~min}$ incubation, low-molecular-weight impurities were removed using PD-10 column (GE Healthcare, Sweden), and $\mathrm{CN}$-2-pyridyldithio-end group (1) was produced as shown in Figure 1(a).

(b) Reduction of 2-Pyridyldithio Group. To yield CN with $\mathrm{S}-\mathrm{H}$ end group (2), $0.4 \mathrm{~mL}$ dithiothreitol (DTT, $0.05 \mathrm{M}$ ) in $0.1 \mathrm{M}$ phosphate buffer $\mathrm{pH} 7.4$ was added to $0.2 \mathrm{~mL}$ of product (1) as shown in Figure 1(b). The mixture was incubated for $60 \mathrm{~min}$. 
(c) Synthesis of CN-TAT-Peptide. $0.5 \mathrm{~mL}$ TAT-peptide (2.5 to $0.16 \mathrm{mg} / \mathrm{mL}$ ) in phosphate buffer $\mathrm{pH} 7.4$ was added to $0.5 \mathrm{~mL}$ of $\mathrm{CN}$ with $\mathrm{S}-\mathrm{H}$ end group (2). The mixture was incubated overnight to allow formation of disulphide links between $\mathrm{CNs}$ with $\mathrm{S}-\mathrm{H}$ end group and TAT-peptide. The resultant CN-TAT (3) as shown in Figure 1(c) was identified and collected using HPLC method.

2.2.3. Determination of Particles Size and Zeta Potential of Conjugated $C N$. Particle size ( $Z$ average) and zeta potential of CN-TAT were characterized using a Malvern Zetasizer (Zetasizer Nano ZS, Malvern, UK). No dilutions were performed during the analysis. Each sample was analysed in triplicates. The measurements were made at $25^{\circ} \mathrm{C}$.

2.2.4. CN-TAT Identification. HPLC (Shimadzu LC-20 AT, USA) gradient mode was applied to identify conjugated product [14]. The mobile phase used was acetonitrile and water containing $0.05 \%$ trifluoroacetic acid, and the flow rate applied was $1 \mathrm{~mL} / \mathrm{min}$ using $5-20 \%$ acetonitrile over the course of $40 \mathrm{~min}$. Column used was Inertsil ODS-3 (4.6 $\times 250 \mathrm{~mm}$ ), and absorbance was measured at $220 \mathrm{~nm}$. On the other hand, the presence of disulphide bond that linked
TAT-peptide onto the $\mathrm{CN}$ surface was determined using Raman spectrometer (Raman Micro 200, Perkin Elmer Inc., USA). Sample of conjugated CN-TAT was freeze-dried prior to analysis. Disulphide linkage was confirmed by the presence of a peak at a range between 425 and $550 \mathrm{~cm}^{-1}$ [13].

2.2.5. Adsorption of siRNA onto CN-TAT. A fixed amount of siRNA $(1.65 \mu \mathrm{g})$ was adsorbed on CN-TAT surface by adding $500 \mu \mathrm{L}$ siRNA solution dropwise to $500 \mu \mathrm{L}$ CN-TAT $(1.5 \mathrm{mg})$ in deionised double-distilled water, and the interaction tubes were inverted up and down. The mixture was then incubated for $2 \mathrm{~h}$ at room temperature. Adsorption of siRNA onto $\mathrm{CN}$ was carried out by the same protocol as above.

2.2.6. siRNA Loading Efficiency. siRNA loading efficiency of $\mathrm{CN}-\mathrm{TAT}$ and $\mathrm{CN}$ was obtained from determination of free siRNA concentration in supernatant recovered from nanoparticles suspension after centrifugation process $(48,583 \times \mathrm{g}, 30 \mathrm{~min})$ using a UV-Vis spectrophotometer (Shimadzu 1800) at $260 \mathrm{~nm}$. Supernatants collected from empty CN-TAT or CN were used as a blank/reference. siRNA loading efficiency (\%) was calculated using the following formula:

$\frac{\text { (concentration of siRNA added }- \text { concentration of siRNA in supernatant) }}{\text { concentration of siRNA added }} \times 100$.

2.2.7. siRNA Binding Efficiency. After siRNA was adsorbed onto the CN-TAT and $\mathrm{CN}, 20 \mu \mathrm{L}$ of sample (containing $16.5 \mathrm{ng}$ siRNA) was loaded to each well of $2 \% \mathrm{w} / \mathrm{v}$ agarose gel with SYBR green (Invitrogen). Free siRNA was used as positive control, while unloaded CN-TAT and CN were used as negative controls. Electrophoresis was run for $26 \mathrm{~min}$ as per supplier's protocol (2005-2006 Invitrogen Corporation). The siRNA bands were then visualised using real-time UV transilluminator (Invitrogen).

2.2.8. Cytotoxicity Study. V79 cells were seeded in a 96well plate at a density of $5 \times 10^{3}$ cells per well in DMEM containing 5\% FBS and $1 \%$ penicillin-streptomycin. The cells were grown overnight at $37^{\circ} \mathrm{C}, 5 \% \mathrm{CO}_{2}$. After $24 \mathrm{~h}$ after incubation of empty and adsorbed CN-TAT with siRNA (200 $\mu \mathrm{L}$ per well containing $1.5 \mathrm{mg} / \mathrm{mL}$ of nanoparticles) at $37^{\circ} \mathrm{C}$, a final dilution of $1 / 10$ per cells volume of Alamar Blue reagent was added to the treated cells and followed by $4 \mathrm{~h}$ incubation prior to analysis. Fluorescence intensity was analysed at $\lambda_{\mathrm{ex}}=570 \mathrm{~nm}$ and $\lambda_{\mathrm{em}}=585 \mathrm{~nm}$ using a microplate reader.

\section{Results and Discussion}

3.1. Particle Size and Surface Charge. Generally, the particle size of nonconjugated $\mathrm{CN}$ was less than $300 \mathrm{~nm}$, and the zeta potential varied with different concentrations of chitosan used (from $0.1-0.3 \% \mathrm{w} / \mathrm{v}$ ) ranging from +30 to $+50 \mathrm{mV}$ (data not shown). For this conjugation, $\mathrm{CN}$ was prepared from $0.2 \% \mathrm{w} / \mathrm{v}$ of chitosan, and conjugation of $\mathrm{CN}$ with the TAT-peptide was performed in various TAT-peptide-to$\mathrm{CN}$ weight ratios ranging from $0.008: 1$ to $0.125: 1$. After conjugation with TAT-peptide, particle size was significantly increased from $352 \pm 44.2$ to $594 \pm 23.5 \mathrm{~nm}$ when TATpeptide concentration was decreased from 2.5 to $0.16 \mathrm{mg} / \mathrm{mL}$ (TAT-peptide-to-CN weight ratio of $0.125: 1$ to $0.008: 1$ ) (Figure 2). The smallest particle size was obtained when the weight ratio was $0.125: 1$ or when the concentration of TAT peptide was $2.5 \mathrm{mg} / \mathrm{mL}$. In general, an increase in particle size after conjugation is expected since polymer chains of conjugated TAT-peptides are extended on the surface of $\mathrm{CN}$. However, a clear trend on the relationship between TATpeptide-to-CN weight ratio and particle size of conjugated $\mathrm{CN}$ could not be determined in this study. Particle size of loaded CN-TAT with siRNA was in nano-sized range and constantly increased for TAT-peptide to $\mathrm{CN}$ weight ratio from $0.063: 1$ to $0.008: 1$. However, below this range (TATpeptide to $\mathrm{CN}$ weight ratio of $0.125: 1)$, the particle size was larger than $1 \mu \mathrm{m}$. In addition, at the weight ratios of $0.03: 1$ and $0.016: 1$, particle size of loaded CN-TAT with siRNA remained similar to the empty CN-TAT. The zeta potential on the other hand was reduced to almost neutral (between -0.4 and $-0.6 \mathrm{mV}$ ) after conjugation with TAT-peptide. The conversion of these particles from positively to negatively charged could be due to the phosphate buffer, used to dilute 


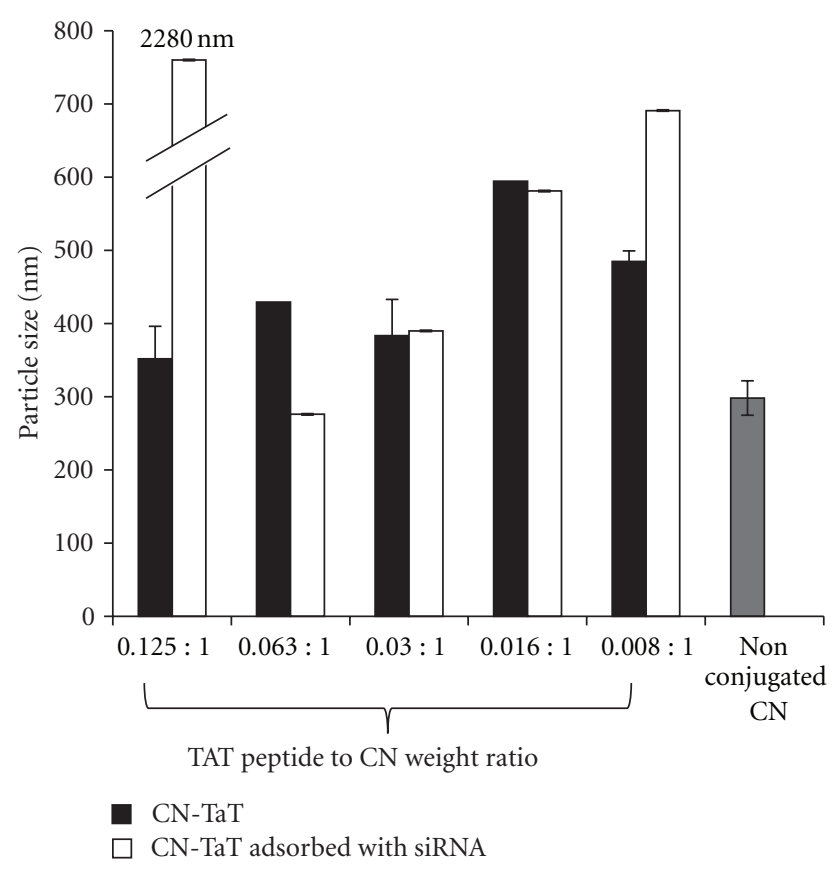

Figure 2: Particle size of empty CN-TAT and CN-TAT with adsorbed siRNA at different TAT-peptide-to-CN weight ratios $(n=3)$.

the TAT-peptide solution. It was found that PBS may conceal the positive charge of chitosan as well as the TAT-peptide, and as a result, the mobility decreases [15]. A further reduction to $-20 \mathrm{mV}$ was observed after adsorbing siRNA onto the CN-TAT surface. This reduction is possibly due to the presence of siRNA on the CN surface.

3.2. Identification of CN-TAT-Peptide. HPLC chromatogram of sample collected from conjugation process was compared with the chromatogram of standard TAT-peptide to determine the presence of conjugated TAT-peptide with CN. Figure 3(a) shows the absence of peak for nonconjugated $\mathrm{CN}$. This therefore suggested that the non-conjugated $\mathrm{CN}$ would not associate with the peak appearance of standard and conjugated TAT. Figure 3(b) shows the peak of standard TAT appearing at $17.365 \pm 0.035 \mathrm{~min}$, while Figure 3 (c) shows two peaks appearing at 17.863 and 21.268 min for the sample collected from conjugation process. The first peak appearing at the same retention time with the peak of standard TAT peptide indicated the presence of free TAT-peptide. On the other hand, the second peak appearing at $21.268 \mathrm{~min}$ may indicate the presence of conjugated TAT-peptide. Further analysis to identify peak of the conjugated TAT peptide was done by injecting $20 \mu \mathrm{L}$ of standard TAT-peptide directly into the conjugated sample through HPLC autosampler, and it was analysed immediately. Figure 3(d) shows that area of the first peak at 17.863 min was increased. Similarly, the ratio between mean peak areas 1 and 2 shows an increment from 0.9: 1 to $1.3: 1$ after spiking with the standard TAT-peptide. As a consequence, this further suggested that peak 1 and peak 2 represent free and conjugated TAT-peptide, respectively.
Based on the HPLC analysis, it was also observed that percentage of TAT-peptide conjugated onto $\mathrm{CN}$ increased from 7 to $13 \%$ when TAT-peptide-to-CN weight ratio was increased from 0.008 to $0.03: 1$. However, further increase of TAT-peptide-to-CN weight ratio to $0.125: 1$ did not result in the increment of conjugated TAT-peptide. Instead, the percentage was reduced from 13 to $6 \%$. The reduction in the conjugation was expected as interaction between $\mathrm{CN}$ and TAT-peptide was dependent on the number of $\mathrm{S}-\mathrm{H}$ groups on $\mathrm{CN}$, and it had reached maximum at the weight ratio of $0.03: 1$. Above this point, all S-H groups available on $\mathrm{CN}$ had been interacted with S-H groups of TAT-peptides. Further increment of TAT-peptide therefore could not increase the percentage of conjugation. Instead, the presence of more TAT-peptides in the reaction medium would reduce the percentage of conjugation by competitively inhibiting the interaction between $\mathrm{CN}$ and TAT-peptide.

To further determine the presence of disulphide linkage or S-S bond between CN and TAT-peptide, Raman spectroscopy was used. Raman spectrum in Figure 4 could be related to the proposed mechanism of reaction between CN, SPDP DTT, and TAT-peptide as shown in Figure 1. The reaction started when the carbonyl group of SPDP reacted with the primary amine group of $\mathrm{CN}$ to form intermediate $\mathrm{CN}$ product containing 2-pyridyldithio end group (1) (Figure 1). 2-pyridyldithio end group in the intermediate $\mathrm{CN}$ product (1) (Figure 1) was reduced using DTT to form CN-S-H (2) (Figure 1), and as shown in the spectrum (Figure 4(c)), a peak at $2560.15 \mathrm{~cm}^{-1}$ indicated the presence of S-H bond in (2). The presence of $\mathrm{S}-\mathrm{H}$ bond in the TAT-peptide was identified by a peak appeared at $2573.15 \mathrm{~cm}^{-1}$ (Figure $4(\mathrm{~b})$ ). Product (2) (Figure 1) was then reacted with S-H containing TAT-peptide and produced CN-TAT conjugates by forming S-S bond (3) (Figure 1). Spectrum (d) in Figure 4 shows the appearance of a peak at $545.52 \mathrm{~cm}^{-1}$ which indicated that $\mathrm{S}-\mathrm{S}$ bond was formed between $\mathrm{CN}$ and TAT-peptide. It was also observed that a strong peak appeared at a wavenumber of $920 \mathrm{~cm}^{-1}$ (Figure $4(\mathrm{~d})$ ) which indicated the presence of $\mathrm{C}-\mathrm{O}-\mathrm{C}$ bond of $\mathrm{CN}$ glycosidic ring. This finding therefore demonstrated that TAT-peptide was conjugated to $\mathrm{CN}$ via disulfide linkage. It could also exclude the possibility of the product to consist of TAT-TAT dimer.

3.3. siRNA Loading and Binding Efficiency. siRNA was adsorbed onto the surface of $\mathrm{CN}$ and CN-TAT. The interaction between CN-TAT and siRNA was therefore via electrostatic interaction between oppositely charged molecules. A TAT-peptide-to-CN weight ratio of $0.03: 1$ was used for CN-TAT since it produced the highest percentage of TATpeptide conjugated onto CN. From the results obtained, it was found that conjugated $\mathrm{CN}$ was able to adsorb siRNA. Loading efficiency for siRNA adsorbed onto the CN-TAT surface was $93 \% \pm 0.01$. In contrast, loading efficiency for $\mathrm{CN}$ by the same siRNA loading method was $88 \% \pm 1.42$. To further assess siRNA binding onto CN-TAT, gel mobility shift was used. In this experiment, siRNA was adsorbed onto the fixed amount of particles with different TAT-peptideto- $\mathrm{CN}$ weight ratios, ranging from $0.125: 1$ to $0.008: 1$ 


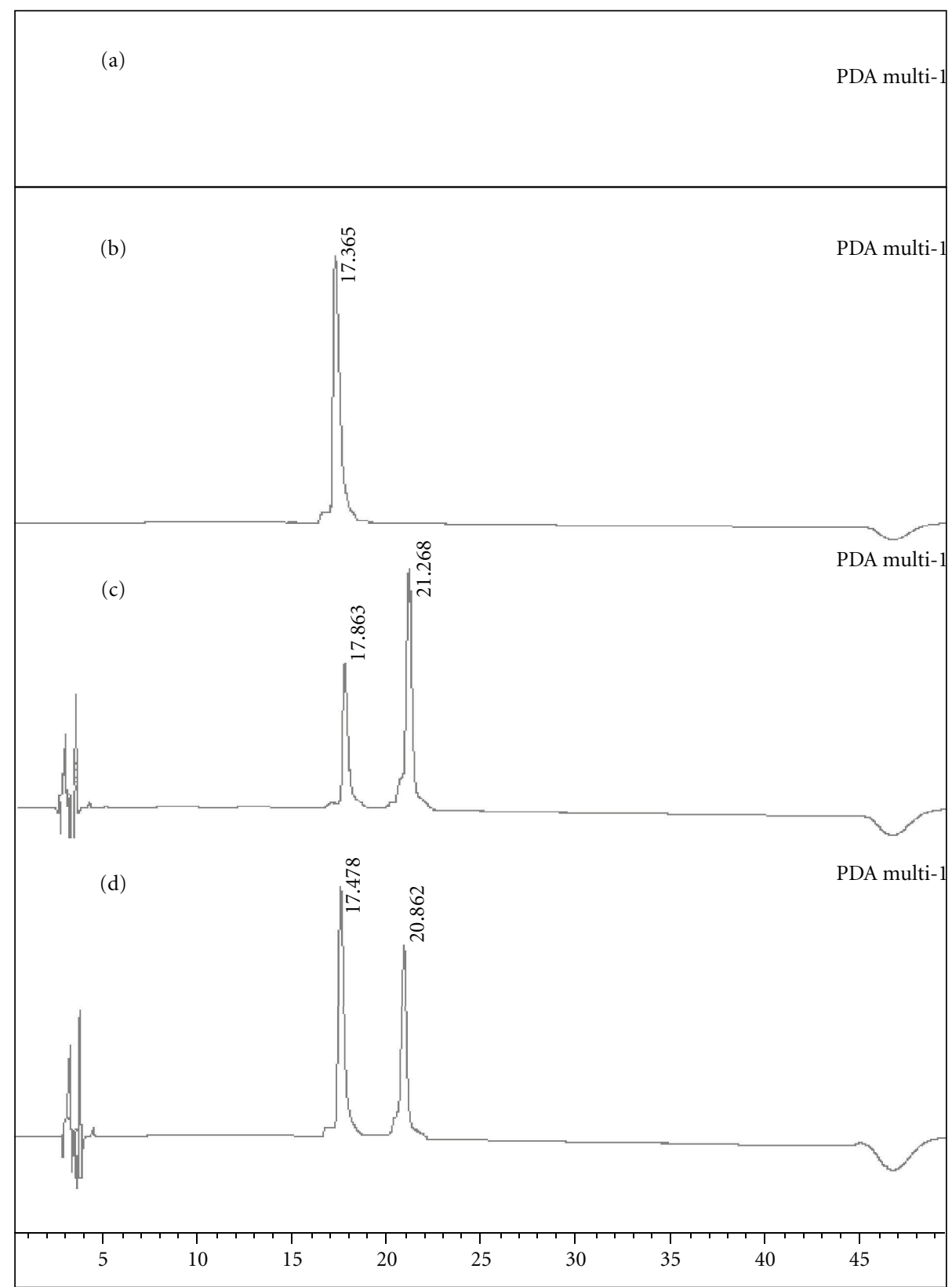

Figure 3: HPLC chromatograms of (a) nonconjugated CN, (b) standard TAT, (c) conjugated TAT, and (d) spiked TAT-peptide.

and at TAT-peptide-to-siRNA weight ratio ranging from $3: 1$ to $0.2: 1$. Agarose gel electrophoresis showed smearing appearance of some bands which may indicate heterogeneity in electrophoretic behavior [16]. It appeared that siRNA was strongly absorbed onto the particles at a TAT-peptide to CN weight ratio of $0.063: 1$ and above (TAT-peptide to siRNA weight ratio $\geq 1.5: 1$ ). Below this point, trailing bands were observed which indicated the presence of free siRNA which had been released or unbound to the CN-TAT (Figure 5). This may result from the less number of TAT-peptide available to interact with siRNA as the presence of arginine and lysine residues within the TAT-peptide contributes to the highly cationic charge of the TAT-peptide and subsequently interaction with negatively charged siRNA.
3.4. Cytotoxicity Effects. The effect of CN-TAT on cytotoxicity was measured by cell viability determination, calculated as a percentage of the cell viability of untreated cell. Alamar blue assays were performed to investigate the presence of any cytotoxicity to the treated cells from the CN-TAT in terms of inhibition of growth or cell death. No significant reduction in cell viability could be seen in the cells treated with the $\mathrm{CN}$-TAT at the different TAT-peptide-to-CN weight ratios at $24 \mathrm{~h}$ after incubation (Figure 6(a)). Over $90 \%$ average cell viability was observed in comparison to untreated cells. Significant reduction in cell viability was also not detected when the cells were treated with CN-TAT adsorbed with siRNA (Figure 6(b)). Contrary to that, a significant reduction in cell viability was detected after exposure of 


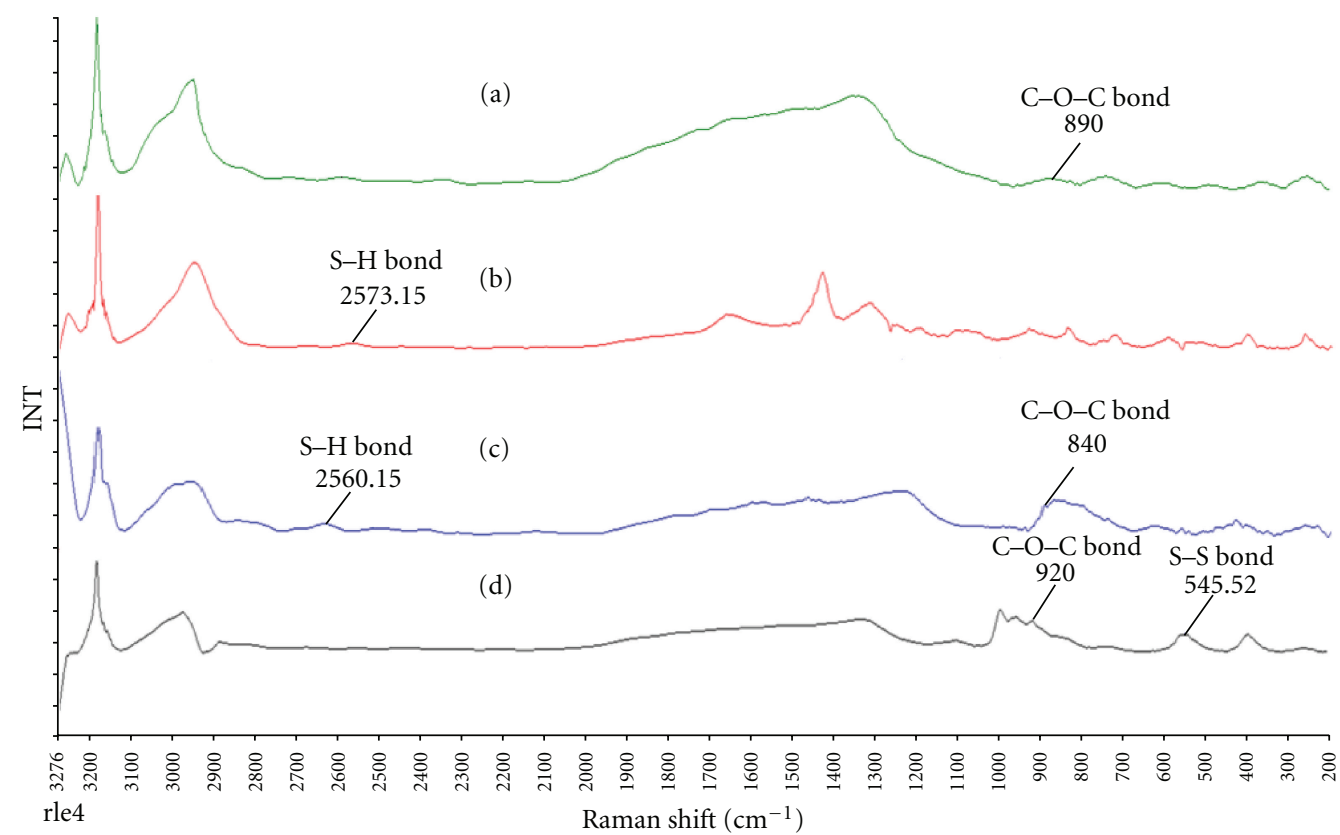

FIGURE 4: Raman spectrum of (a) CN (absence of S-H or S-S bond), (b) TAT-peptide (containing S-H bond at $2573.15 \mathrm{~cm}^{-1}$ ), (c) CN-S-H end group at $2560.15 \mathrm{~cm}^{-1}$, and (d) CN-TAT-peptide containing S-S bond at $545.52 \mathrm{~cm}^{-1}$. S-S bond wavenumber range is between 425 and $550 \mathrm{~cm}^{-1}$, and $\mathrm{C}-\mathrm{O}-\mathrm{C}$ wavenumber range is between 800 and $950 \mathrm{~cm}^{-1}[13]$.

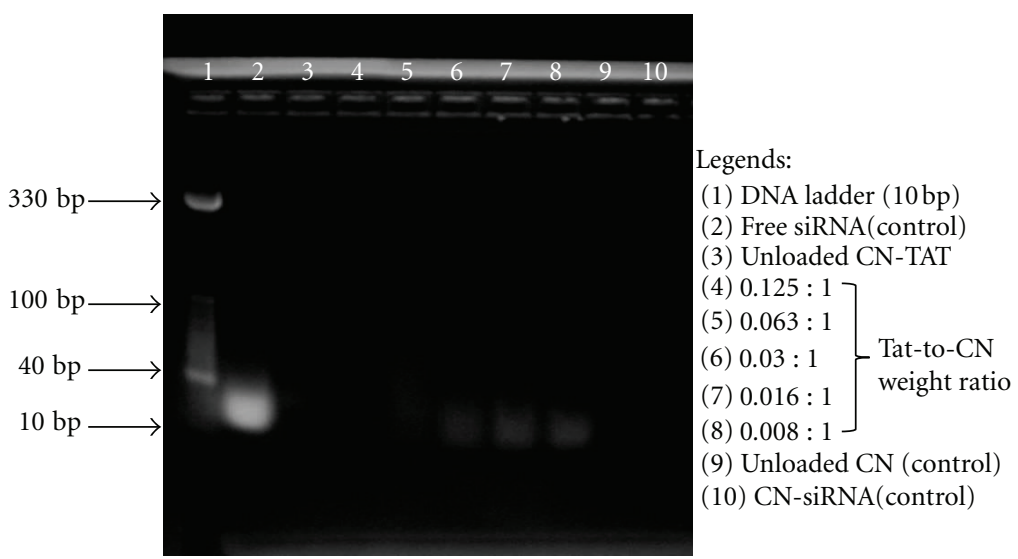

FIGURE 5: Electrophoretic mobility of adsorbed siRNA onto CN-TAT.

cells with CN and TAT-peptide, respectively. The cytotoxicity effect of these two was closely related to the high density of their positive charge (e.g., zeta potential for $\mathrm{CN}$ was more than $+30 \mathrm{mV}$ ) as no charge neutralisation by siRNA occurs in the case of individual CN and TAT-peptide. Furthermore, a slight loss in cell viability could still be seen for $\mathrm{CN}$ even though these particles were adsorbed with siRNA. These findings, therefore, suggested that CN-TAT has relatively low toxicity and therefore has a great potential to be used as a vector for intracellular delivery of siRNA. To further investigate its use in siRNA delivery, a series of on-going investigations on the ability of CN-TAT to deliver siRNA into cells and induce silencing of the targeted genes are currently being performed in cultured cells in vitro.

\section{Conclusions}

TAT-peptide was successfully conjugated onto CN via disulphide linkage, and the system has shown to have the ability to carry siRNA with high loading efficiency and is relatively nontoxic to living cells. As a conclusion, CN-TAT holds promise as a potentially new gene delivery system.

\section{Funding}

The authors gratefully acknowledge the financial support of this research by Ministry of Science, Technology and Innovation, Malaysia with Grant no. 02-01-02-SF0502. 


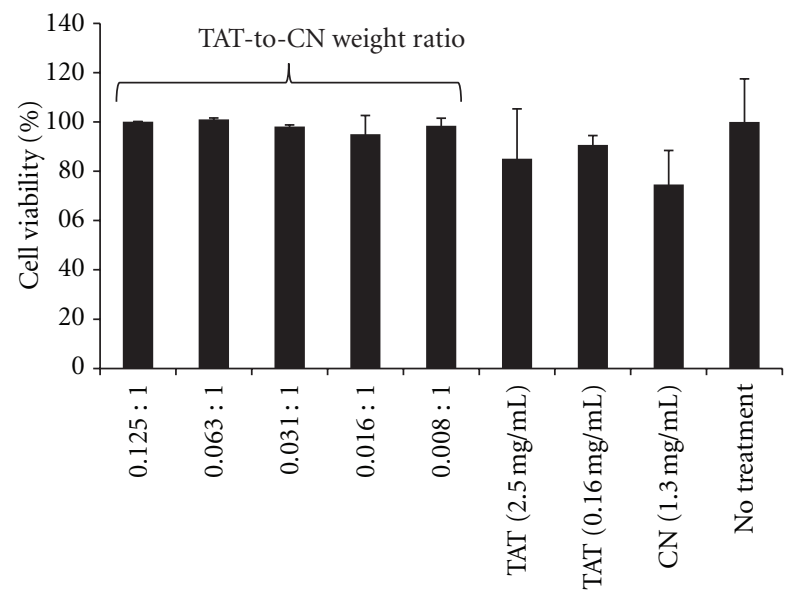

(a)

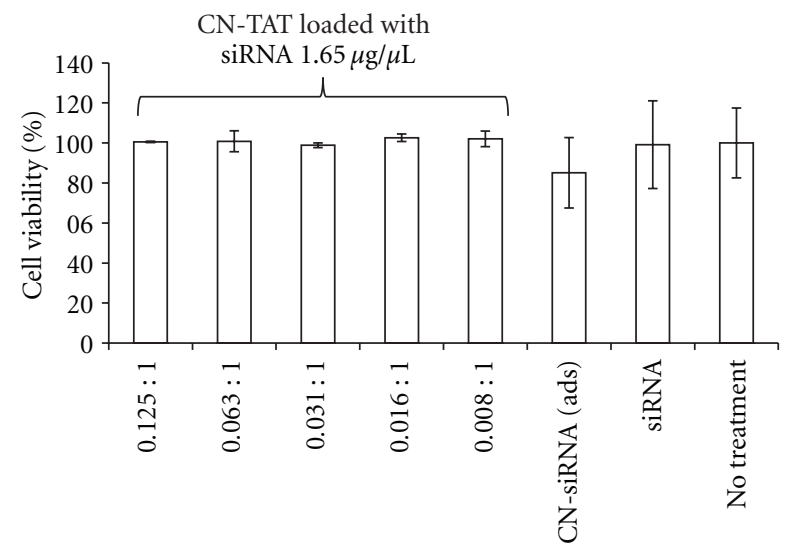

(b)

Figure 6: Cell viability (\%) of (a) CN-TAT at different TATpeptide-to-CN weight ratios and (b) CN-TAT adsorbed with siRNA $(n=6)$. CN-TAT and CN were adsorbed with $1.65 \mu \mathrm{g}$ siRNA. ${ }^{* *} 2.5$ and $0.16 \mathrm{mg} / \mathrm{mL}$ TAT-peptide represent the highest and lowest concentration of the individual TAT-peptide, and they were equivalent to the amount of TAT peptide used in CN-TAT conjugation process at TAT-peptide-to- $\mathrm{CN}$ weight ratios $0.125: 1$ and $0.008: 1$, respectively.

\section{Acknowledgment}

The authors would like to thank all members of UKM Drug Delivery and Novel Targeting Research Group for their support.

\section{References}

[1] J. H. Felgner, R. Kumar, C. N. Sridhar et al., "Enhanced gene delivery and mechanism studies with a novel series of cationic lipid formulations," Journal of Biological Chemistry, vol. 269, no. 4, pp. 2550-2561, 1994.

[2] F. Liu and L. Huang, "Development of non-viral vectors for systemic gene delivery," Journal of Controlled Release, vol. 78, no. 1-3, pp. 259-266, 2002.

[3] T. H. Kim, H. L. Jiang, D. Jere et al., "Chemical modification of chitosan as a gene carrier in vitro and in vivo," Progress in Polymer Science, vol. 32, no. 7, pp. 726-753, 2007.
[4] T. G. Park, J. H. Jeong, and S. W. Kim, "Current status of polymeric gene delivery systems," Advanced Drug Delivery Reviews, vol. 58, no. 4, pp. 467-486, 2006.

[5] H. Katas and H. O. Alpar, "Development and characterisation of chitosan nanoparticles for siRNA delivery," Journal of Controlled Release, vol. 115, no. 2, pp. 216-225, 2006.

[6] W. F. Lai and M. C. M. Lin, "Nucleic acid delivery with chitosan and its derivatives," Journal of Controlled Release, vol. 134, no. 3, pp. 158-168, 2009.

[7] H. Brooks, B. Lebleu, and E. Vivès, "Tat peptide-mediated cellular delivery: back to basics," Advanced Drug Delivery Reviews, vol. 57, no. 4, pp. 559-577, 2005.

[8] M. Lindgren, M. Hallbrink, A. Prochiantz, and U. Langel, "Cell-penetrating peptides," Trends in Pharmacological Sciences, vol. 21, pp. 99-103, 2002.

[9] A. Zhao, P. Yao, C. Kang, X. Yuan, J. Chang, and P. Pu, "Synthesis and characterization of tat-mediated $\mathrm{O}-\mathrm{CMC}$ magnetic nanoparticles having anticancer function," Journal of Magnetism and Magnetic Materials, vol. 295, no. 1, pp. 37-43, 2005.

[10] J. Chomoucka, J. Drbohlavova, D. Huska, V. Adam, R. Kizek, and J. Hubalek, "Magnetic nanoparticles and targeted drug delivering," Pharmacological Research, vol. 62, no. 2, pp. 144$149,2010$.

[11] B. Lebleu, H. M. Moulton, R. Abes et al., "Cell penetrating peptide conjugates of steric block oligonucleotides," Advanced Drug Delivery Reviews, vol. 60, no. 4-5, pp. 517-529, 2008.

[12] J. J. Turner, G. D. Ivanova, B. Verbeure et al., "Cell-penetrating peptide conjugates of peptide nucleic acids (PNA) as inhibitors of HIV-1 Tat-dependent trans-activation in cells," Nucleic Acids Research, vol. 33, no. 21, pp. 6837-6849, 2005.

[13] E. Smith and G. Dent, Modern Raman Spectroscopy: A Practical Approach, John Wiley \& Sons, West Sussex, UK, 2006.

[14] S. Kida, M. Maeda, K. Hojo et al., "Design and synthesis of a Tat-related gene transporter: a tool for carrying the adenovirus vector into cells," Bioorganic and Medicinal Chemistry Letters, vol. 16, no. 3, pp. 743-745, 2006.

[15] T. López-León, E. L. S. Carvalho, B. Seijo, J. L. Ortega-Vinuesa, and D. Bastos-González, "Physicochemical characterization of chitosan nanoparticles: electrokinetic and stability behavior," Journal of Colloid and Interface Science, vol. 283, no. 2, pp. 344351, 2005.

[16] P. Medberry, S. Dennis, T. Van Hecke, and R. K. DeLong, "pDNA bioparticles: comparative heterogeneity, surface, binding, and activity analyses," Biochemical and Biophysical Research Communications, vol. 319, no. 2, pp. 426-432, 2004. 

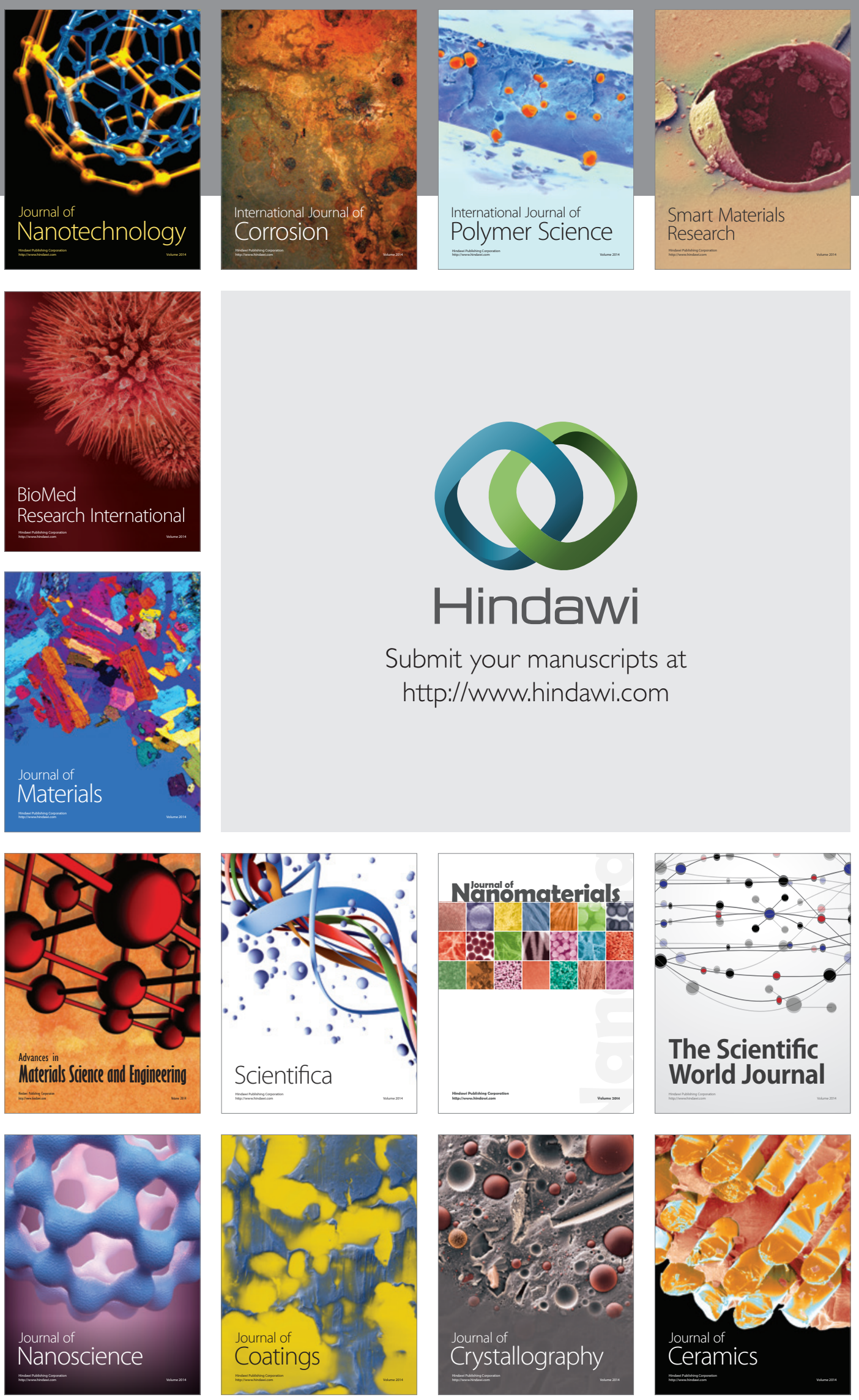

The Scientific World Journal

Submit your manuscripts at

http://www.hindawi.com

\section{World Journal}

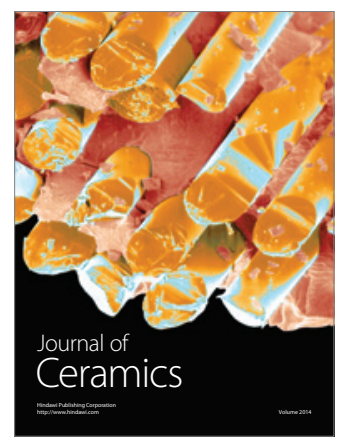

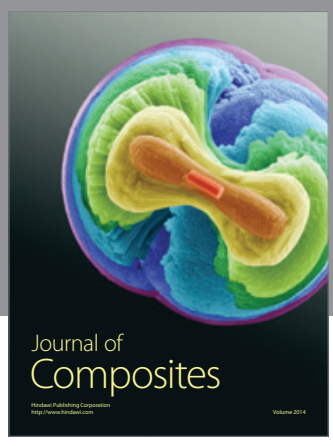
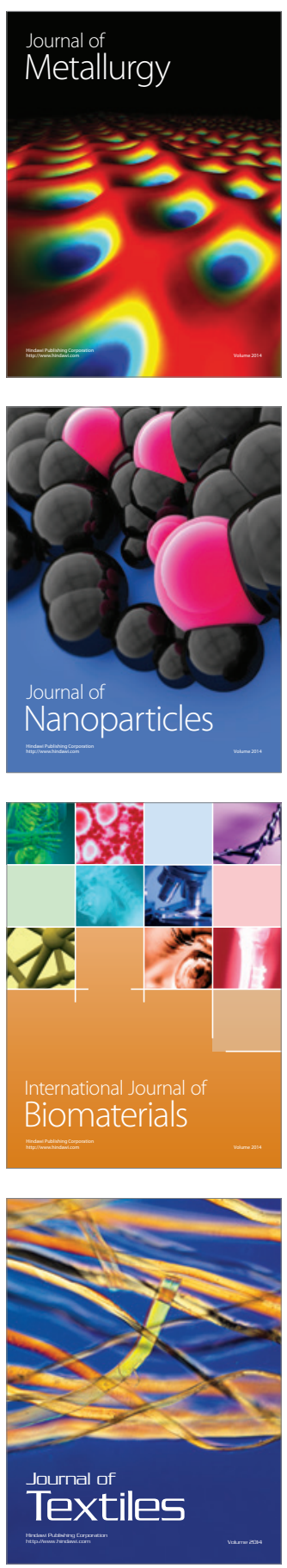